\title{
Ultrasonic Monitoring of Ply Crack and Delamination Formation in Composite Tube Under Torsion Load
}

\author{
P. H. Johnston, C. W. Wright, J. N. Zalameda \\ NASA Langley Research Center \\ Hampton, VA, USA \\ Patrick.H.Johnston@nasa.gov
}

\author{
J. P. Seebo \\ Lockheed Martin Corporation \\ Hampton, VA, USA
}

\begin{abstract}
As a simple model of a rotor spar, a circular graphiteepoxy composite laminate cylinder was subjected to cyclic torsional load. The test section of the cylindrical specimen varied from four to six plies of $\pm 45^{\circ}$ fibers, due to intentional ply overlaps and gaps. A layer of $13-\mu \mathrm{m}$ Teflon film was inserted between plies at three locations to serve as delamination initiators. A commercial X-Y scanner was mounted to the load frame to enable ultrasonic inspection without removing the specimen. A focused immersion probe was mounted in a captive water column with a rugged Nitrile membrane tip, which was coupled to the cylinder using a mist of soapy water. The transducer was aligned normal to the cylinder surface using the $\mathrm{X}$-axis. Scanning was performed along the length of the specimen with the $\mathrm{Y}$-axis and the specimen was incrementally rotated by the torsion head of the load frame. After $350 \mathrm{k}$ cycles of torsion, several linear $45^{\circ}$ diagonal indications appeared as $5-40 \%$ attenuation of the back wall echo, with no apparent echoes from the interior of the composite, suggesting through-ply cracks in the innermost ply. Crack indications grew and new cracks appeared as torsion cycling continued. Internal reflections from delaminations associated with the growing ply cracks appeared after 500k cycles. Three areas of extensive multi-layer delaminations appeared after 1150k cycles. Failure of the specimen occurred at $1600 \mathrm{k}$ cycles. The observed progressive damage was not associated with the Teflon inclusions. Concurrent thermographic measurements provided lowerresolution confirmation of the damage observed.
\end{abstract}

Keywords- composites, ultrasonic, in situ

\section{INTRODUCTION}

A helicopter rotor spar is subjected to tremendous tensile and torsional loading. Under the NASA Aircraft Aging and Durability Program and a Center for Rotorcraft Innovation Space Act Agreement with Sikorsky Helicopter, NASA researchers are developing computational methods to predict the growth of damage in graphite-epoxy rotor spars. Verification of these computational models requires highfidelity nondestructive methods to obtain high-resolution characterization of the damage as it progresses. In the current study, a circular composite laminate cylinder, as a simple model of a rotor spar, was subjected to cyclic torsional load.

An objective of this work was to demonstrate the efficacy of a load frame mounted nondestructive measurement system to perform inspections in situ. It was desired to monitor the state of the cylinder both during active loading and at rest. Because of its non-contact nature, thermography was selected for use during active cyclic loading. Ultrasonic inspection was chosen to provide high-resolution characterization of the growth of induced damage in the cylinder.

This paper will present a description of the cylindrical composite specimen and the torsional load test, followed by a description of the thermographic and ultrasonic measurement systems employed. The next section will describe the damage observations based on the ultrasonic and thermographic results, followed by concluding remarks.

\section{TORSIONAL TESTING OF COMPOSITE CYLINDER}

\section{A. Composite Cylinder}

A picture of the composite cylinder is shown in Fig. 1. The overall length of the cylinder was approximately $51 \mathrm{~cm}$. The test section of the cylindrical specimen was $8.1 \mathrm{~cm}$ in diameter, $25.4 \mathrm{~cm}$ long, and varied between four to six plies of $\pm 45^{\circ}$ fibers, due to intentional ply overlaps and ply gaps around the circumference. The cylinder was built up in thickness at each end, where steel fixtures were bolted in place for attaching the specimen to the load frame.

Three $13 \mu \mathrm{m}$ thick Teflon inserts, labeled A, B, and C in Fig. 1, were placed in the composite wall. Inserts A and C, each $1.27 \mathrm{~cm} \mathrm{X} 1.27 \mathrm{~cm}$, lay just under the outer surface of the composite, while insert $\mathrm{B}, 0.63 \mathrm{~cm} \mathrm{X} 0.63 \mathrm{~cm}$, lay just inside the inner surface. The inserts were intended to simulate preexisting delamination damage and serve as possible damage growth initiation sites.

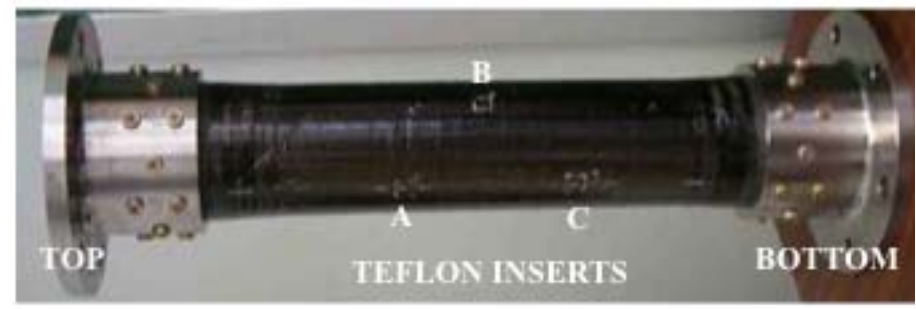

Figure 1. Photograph of the composite cylinder specimen. Labels A, B and C indicate the locations of Teflon inserts. 


\section{B. Torsional Test}

The test load for this cylinder was cyclic torsion, with no axial load. The cylinder was fixed at the upper grip, while the lower grip applied oscillating load between -102,000 N-cm and $+113,000 \mathrm{~N}-\mathrm{cm}$ at a rate of $4 \mathrm{~Hz}$. At intervals, the cycling was paused to permit ultrasonic and thermal scanning. During the middle portion of each set of cycles, passive thermal data was acquired.

Damage initiation and growth was expected to occur at ply drops, ply gaps and ply overlaps, in addition to insert locations.

\section{MEASUREMENT SYSTEMS}

\section{A. Mechanical Scanner}

A commercial X-Y scanner was modified to mount to the support columns of a load frame, with one axis vertical and the other horizontal. Adapters were built to support either an ultrasonic search tube or an IR camera, as shown in Fig. 2. For this study, the horizontal X-axis was used to center either the IR camera or the ultrasonic search tube on the central diameter of the specimen. For thermography, the Y-axis was adjusted to center the specimen in the field of view of the camera. For ultrasonics, the Y-axis was scanned, while the specimen was rotationally indexed using the torsion head.

\section{B. Thermography}

Because of the expected motion of the specimen during cyclic loading, non-contacting passive thermography was employed to observe the cylinder during active testing. Fig. 2a is a photo of the torsion load frame configured with the thermal measurement system. The thermal camera could observe the facing third of the cylinder directly. Angled infrared mirrors were positioned behind and to either side of the specimen to permit observation of the entire cylinder within the camera view. In addition, a flash tube was mounted inside and on the axis of the composite specimen, which enabled active transmission thermography to be performed under static (or zero) load conditions. A detailed description of this system, the algorithms used to interpret the data and more complete thermal results from this test are presented in [1].

\section{Ultrasonics}

An ultrasonic measurement system was assembled, comprising a commercial pulser/receiver and a 12-bit digitizer board. To achieve high resolution, a focused immersion probe (10 MHz, $1.27 \mathrm{~cm}$ diameter, $5.08 \mathrm{~cm}$ focus) was mounted in a captive water column with a rugged Nitrile membrane tip at the focal point. The membrane was brought in contact with the cylinder and coupling was completed using a mist of soapy water. The transducer was aligned normal to the cylinder surface using the $\mathrm{X}$-axis. Scanning was performed along the length of the specimen with the Y-axis and the specimen was incrementally rotated with the torsion head of the load frame. Because the full range of the torsion head was limited to $110^{\circ}$, a halo fixture was mounted on the scanner to permit mounting of the search tube at four positions, separated by $90^{\circ}$, to permit a full $360^{\circ}$ inspection of the cylinder in four scans. The torsion test system configured for ultrasonic scanning is shown in Fig. 2B. A detailed description of the scanning software is given in $[2,4]$, and an overview of non-immersion coupling applications is found in $[3,4]$.

\section{RESULTS}

\section{A. Ply Crack Initiation and Growth}

Flaw initiation was expected to occur at the Teflon inserts on the front side of the cylinder. In Fig. 3 are peak-peak Cscans of the back wall reflection for the front quadrant of the cylinder at three different points in the cyclic testing. In these images, the inserts appear as dark, highly attenuated rectangular areas. Also visible are benign indications from spiral wrapping and a wrinkle mark on the surface near the lower left insert, as well as some porosity indications, which remained stable throughout the mechanical testing.
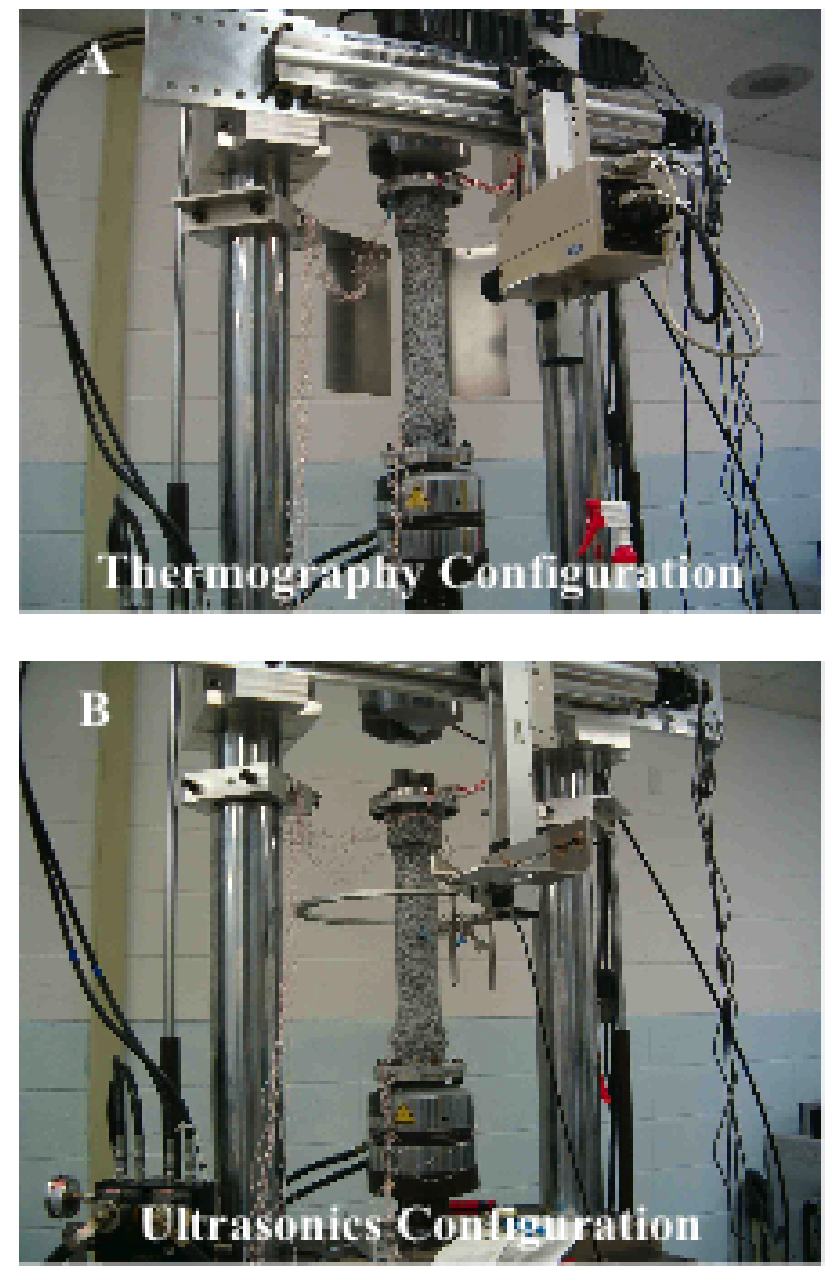

Figure 2. Photographs of the scanning system mounted to the torsional load frame, configured for thermography measurements (A) and for ultrasonic measurements (B). 


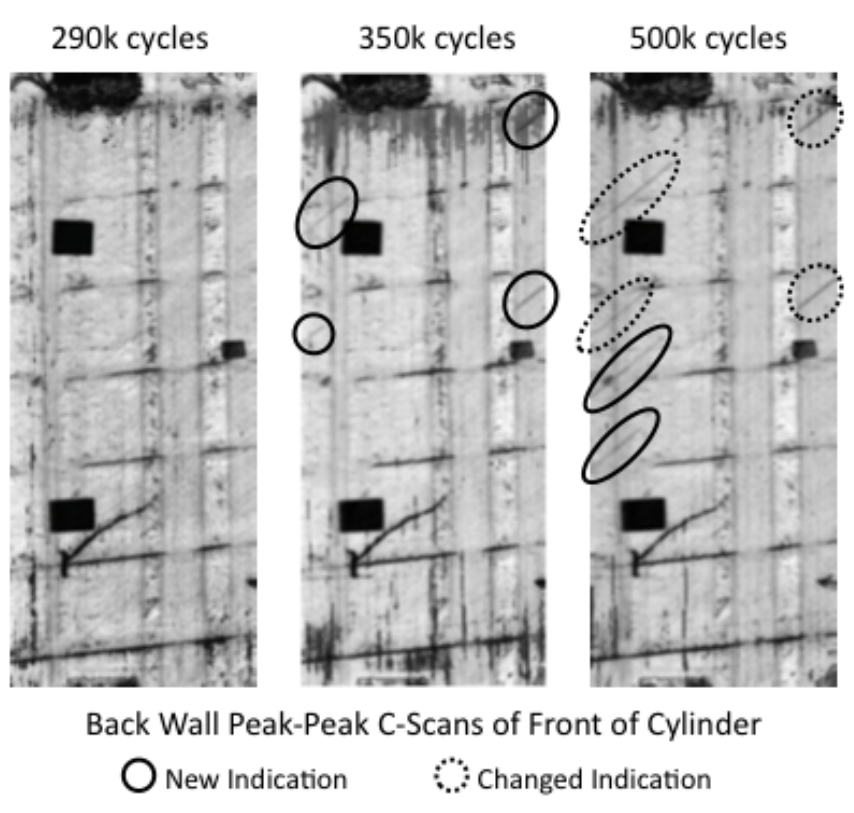

Figure 3. Ultrasonic back-wall C-scans of the front quadrant at 290k, 350k and $500 \mathrm{k}$ cycles. At $290 \mathrm{k}$ cycles, only pre-existing details are observed (inserts, linear surface marks and some areas of porosity). At 350k cycles, new linear $45^{\circ}$ indications appear (circled). Continued cycling to $500 \mathrm{k}$ cycles cause these to grow and more new cracks to appear.

No damage indications were observed though 290,000 cycles. The scan performed after 350,000 cycles several $+45^{\circ}$ linear indications, manifest as $5-40 \%$ attenuation of the back wall echo, with no observable interior echoes. These linear indications, circled in Fig. 3, were consistent with ply cracks in the innermost $+45^{\circ}$-oriented lamina. At 500,000 cycles, these cracks had extended in length and additional cracks had formed in the innermost lamina. No delamination growth was observed near the Teflon inserts.

\section{B. Interior Delamination Formation and Residual Stress}

Fig. 4 presents C-scans made up from scans of the left, front and right quadrants of the cylinder at 550,000 and 600,000 cycles. During this period of loading, new innermost lamina ply cracks continued to form. At several locations, small interior delaminations began to form adjacent to the previously formed ply cracks. No delaminations were observed adjacent to the Teflon inserts. However, after 550,000 cycles, the corners of the inserts $\mathrm{A}$ and $\mathrm{C}$, which lay near the outer surface of the cylinder, began to transmit ultrasound, where they had previously blocked it, suggesting the development of substantial compressive residual stresses at those locations.
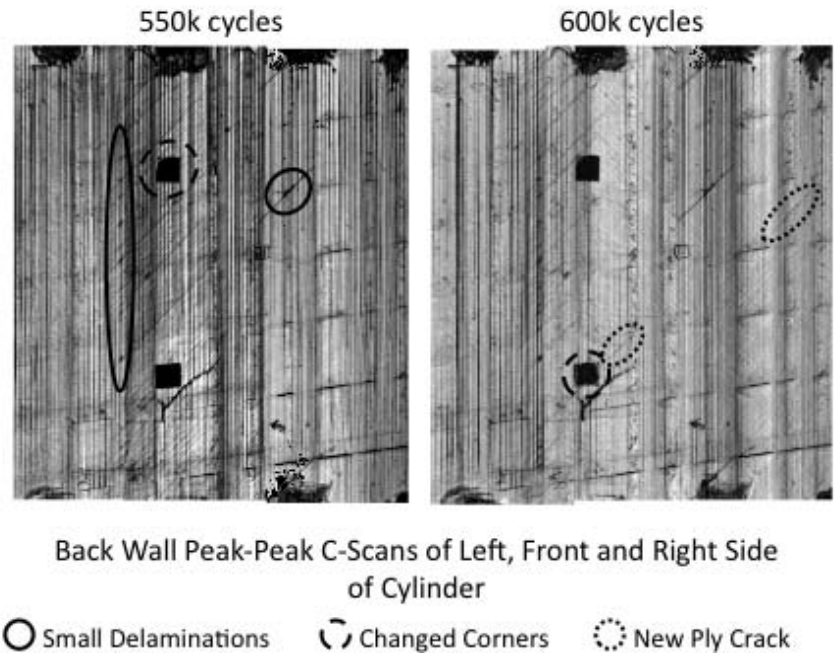

Figure 4. Ultrasonic back-wall C-scans of the left, front and right quadrants taken at 550k cycles and 600k cycles. New ply cracks (dotted ovals) continue to form with loading. Small interior delaminations (solid ovals) begin to form adjacent to the $45^{\circ}$ play cracks. The corners of Teflon inserts A and C (dashed circles) begin to pass ultrasound, suggesting high compressive stress.

\section{Delamination Growth to Failure}

Fig. 5 presents a progression of delamination initiation and growth from 900,000 cycles to $1,450,000$ cycles in the right side quadrant of the specimen. For these C-scans, the gate was placed between the front and back wall echoes, such that signals from interior delaminations appear brighter against a normally dark background. A small delamination is observed just above and to the right of the center of the image, steadily growing in area as the cycling continues. By 1,450,000 cycles this delamination grows rapidly and jumped to other ply interfaces. Two smaller delaminations form grow above and below it.

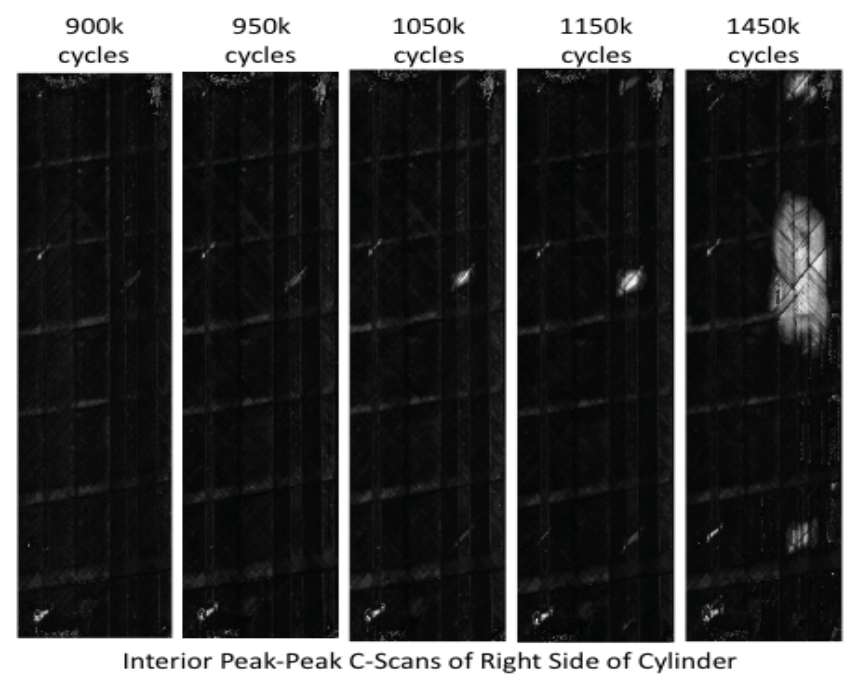

Figure 5. Ultrasonic C-scan images of the right side quadrant of the test cylinder from 900k cycles to 1,450k cycles, showing the initiation and growth of several multi-layer delaminations. 


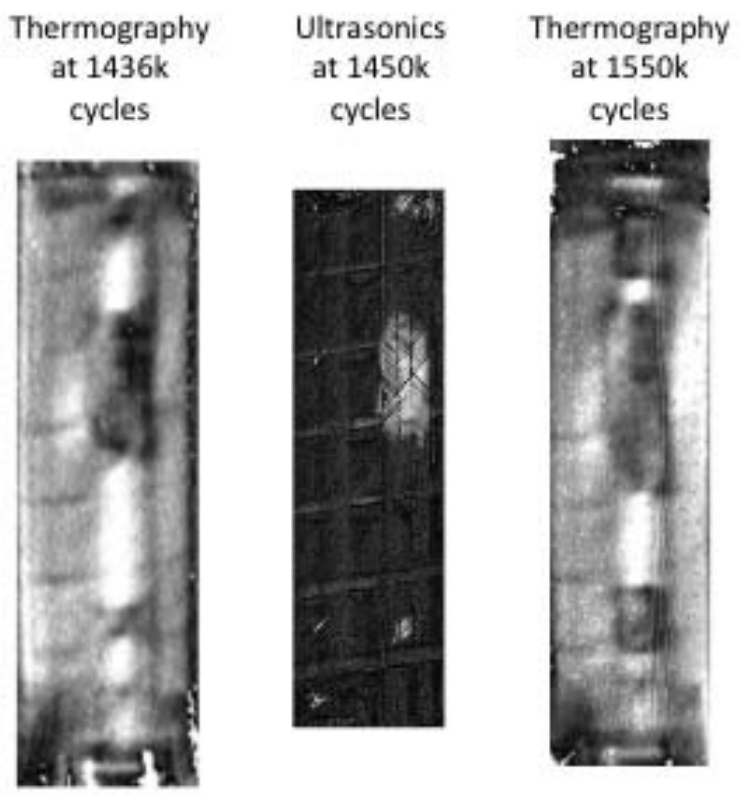

Figure 6. Thermal (left and right) and ultrasonic (center) images showing the delamination growth occurring between $1,436 \mathrm{k}$ cycles and $1,550 \mathrm{k}$ cycles

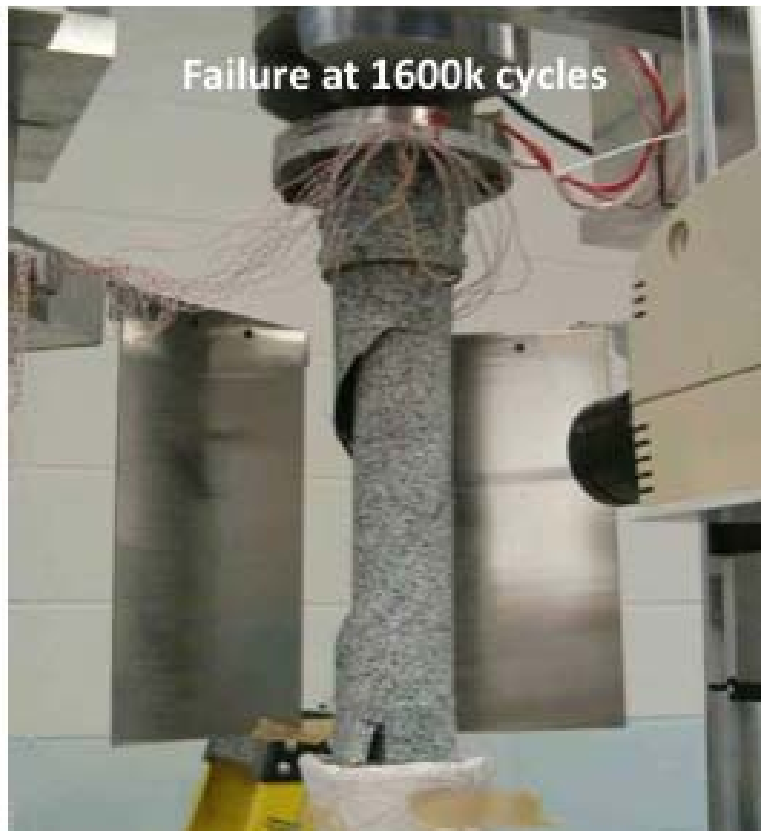

Figure 7. Photograph of the cylinder after failure at $1,600 \mathrm{k}$ cycles.
Fig. 6 shows the ultrasonic data at 1,450,000 again alongside thermographic images taken during cyclic loading at approximately $1,436,000$ and 1,550,000 cycles. The three delaminations observed in the ultrasonic data are also seen in the thermal images. As the cyclic loading was continued past $1,450,000$, the delaminations continue rapid growth in the axial direction and eventually linked up to cause failure of the cylinder at approximately 1,6000,000 cycles. A photograph of the failed specimen, split along the $+45^{\circ}$ orientation, is presented in Fig. 7.

\section{CONCLUSION}

We successfully coupled a mechanical X-Y scanner to a load frame to enable in situ ultrasonic and thermal inspection of composite specimens under various states of load. In this study the thermographic and ultrasonic measurement systems successfully monitored initiation and growth of ply cracks and delaminations in a cylindrical composite laminate under cyclic torsional load.

The ultrasonic measurement system demonstrated excellent sensitivity to through-ply cracks and delaminations. Thermographic measurements were possible during active cyclic loading, and provided lower-resolution interrogation of the damage observed.

\section{ACKNOWLEDGMENT}

The authors thank William M. Johnston for the design of scan system mounting hardware.

\section{REFERENCES}

[1] J. N. Zalameda, W. P. Winfree, J. P. Seebo, and P. H. Johnston, "Thermography Inspection for Detection and Tracking of Composite Cylinder Damage during Load Testing," 2010 Review of Progress in Quantitative Nondestructive Evaluation, San Diego, CA, in press.

[2] J. P. Seebo and P. H. Johnston, "High Speed Position Synchronized Data Acquisition System for In-Situ Ultrasonic Inspection," 2010 ASNT Spring Conference, Williamsburg, VA, unpublished.

[3] P. H. Johnston and J. P. Seebo, "Non-Immersion Coupling Concepts for High-Resolution Ultrasonic Measurements," 2010 Aircraft Airworthiness and Sustainment Conference, Austin, TX, unpublished.

[4] P. H. Johnston and J. P. Seebo, "High Speed Non-Immersion Ultrasonic Measurement System,” NASA Technical Memorandum in preparation, unpublished. 